Supporting Information

\title{
Effect of Monomer Structure on the CuAAC Polymerization to Produce Hyperbranched Polymers
}

Xiaosong Cao, Yi Shi, Weiping Gan, Hannah Naguib, Xiaofeng Wang, Robert Graff, Haifeng Gao*

Department of Chemistry and Biochemistry, University of Notre Dame, Notre Dame, Indiana 46556-5670, United States

* Corresponding author. Email: hgao@nd.edu

Materials. Propionyl chloride (Alfa Aesar, 98\%), triethylamine (Sigma-Aldrich, $\geq 99 \%$ ), pent-4-ynoic acid (Chem-Impex), hept-6-ynoic acid (Alfa Aesar, 95\%), undec-10-ynoic acid (Alfa Aesar, 96\%), pyrene-1-carboxylic acid (TCI, $\geq 97 \%$ ), 3-(3-dimethylaminopropyl)-1-ethyl-carbodiimide hydrochloride $\quad$ (EDC· $\mathrm{HCl}$, Chem-Impex), 4-(dimethylamino) pyridine (DMAP, Sigma-Aldrich, $\geq 99 \%$ ), ascorbic acid (Alfa Aesar, $\geq 99 \%$ ), copper(II) sulfate pentahydrate $\left(\mathrm{CuSO}_{4} \cdot 5 \mathrm{H}_{2} \mathrm{O}, \mathrm{BDH}, \mathrm{ACS}\right.$ grade), $N, N, N^{\prime}, N^{\prime}, N^{\prime}$-pentamethyldiethylenetriamine (PMDETA, Sigma-Aldrich, 99\%), dimethylformamide (DMF, Sigma-Aldrich, $\geq 99.8 \%$ ), ethyl ether (EMD Millipore $\geq 99 \%$ ), methanol (Sigma-Aldrich, $\geq 99.8 \%$ ), deuterated chloroform $\left(\mathrm{CDCl}_{3}\right.$, Alfa Aesar, 99.8\%), dimethyl sulfoxide-d6 (DMSO-d $d_{6}$, Alfa Aesar, 100\%), were used as received. Copper(I) bromide ( $\mathrm{CuBr}$, Sigma-Aldrich, 98\%) was purified 
according to literature procedure. ${ }^{1}$ Tetrahydrofuran (THF, Sigma-Aldrich, $\geq 99 \%$ ) was distilled over sodium benzophenone and dichloromethane (DCM, Sigma-aldrich, > 99.5\%) was distilled over $\mathrm{CaH}_{2}$ prior to use. 2,2-Bis(azidomethyl)propane-1,3-diol, , $^{2}$ 2,3-diazidopropan-1-ol, ${ }^{4} \quad$ 1,3-diazidopropan-2-ol, ${ }^{5} \quad$ 1,4-diazidobutan-2-ol, ${ }^{6}$ methoxypoly(ethylene glycol) acetic acid $(\mathrm{Mn} \sim 350),{ }^{7}$ 2,6-bis-(benzimidazol -2-yl)-pyridine $\quad\left(\operatorname{Py}(\mathrm{BimH})_{2}\right),{ }^{8} \quad \operatorname{tris}((1-$ benzyl-1H-1,2,3-triazolyl)methyl)amine (TBTA) $)^{9}$ were synthesized according to previous literature. Regarding to the explosive nature, all azide compounds were synthesized, purified and stored according to the standard safety rules with caution. ${ }^{10}$

Characterization. The THF size exclusion chromatography (SEC) was equipped with a Waters 515 HPLC pump, Polymer Standards Services (PSS) columns (SDV, $10^{5}, 10^{3}$, and $10^{2} \AA$ ) at $35^{\circ} \mathrm{C}$ with $\mathrm{THF}$ flow rate $=1.00 \mathrm{ml} \mathrm{min}{ }^{-1}$, a differential refractive index (RI) detector (Wyatt Technology, Optilab T-rEX) using PSS WinGPC 7.5 software. The DMF SEC system was equipped with a Waters 515 HPLC pump, Polymer Standards Services (PSS) columns (GRAM, $10^{4}, 10^{3}$, and $10^{2} \AA$ ) at $55^{\circ} \mathrm{C}$

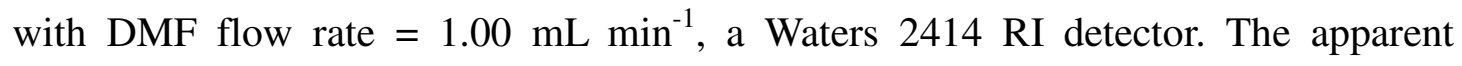
molecular weights were calculated based on linear poly(methyl methacrylate) (PMMA) standards. The detectors employed to measure the absolute molecular weights of hyperbranched polymers in THF SEC were the RI detector and a multi-angle laser light scattering (MALLS) detector (Wyatt Technology, DAWN HELEOS II) with the light wavelength at $658 \mathrm{~nm}$. Absolute molecular weights were determined using ASTRA software from Wyatt Technology, The used dn/dc values 
were determined separately via on-line measurement of each polymer solution at a fixed concentration $\left(3.0 \mathrm{mg} \mathrm{mL} L^{-1}\right)$. The $\mathrm{dn} / \mathrm{dc}$ of each hyperbranched polymer was HBP(S1-S): $0.0930 \mathrm{~mL} \mathrm{~g}^{-1}, \mathrm{HBP}(\mathrm{S} 1-\mathrm{M}): 0.1042 \mathrm{~mL} \mathrm{~g}^{-1}, \mathrm{HBP}(\mathrm{S} 1-\mathrm{L}): 0.1093 \mathrm{~mL} \mathrm{~g}^{-1}$, HBP(R-Py): $0.2092 \mathrm{~mL} \mathrm{~g}^{-1}$, and HBP(R-PEO): $0.0896 \mathrm{~mL} \mathrm{~g}^{-1}$. Proton nuclear magnetic resonance $\left({ }^{1} \mathrm{H}\right.$ NMR), two-dimension homonuclear correlation spectroscopy (COSY), rotating-frame Overhauser effect spectroscopy (ROESY) was acquired on a Bruker $500 \mathrm{MHz}$ spectrometer at $25{ }^{\circ} \mathrm{C}$ using $\mathrm{CDCl}_{3}$ or DMSO- $d_{6}$ as solvent. Differential scanning calorimetry (DSC) analyses were performed under nitrogen purge $\left(50 \mathrm{~mL} \mathrm{~min}{ }^{-1}\right)$ on a DSC Q2000 (TA Instruments) at a heating rate of $10{ }^{\circ} \mathrm{C}$ $\min ^{-1}$ and cooling rate of $10{ }^{\circ} \mathrm{C} \min ^{-1}$. The thermograms were reported based on the second heating cycle in the temperature range of $-100 \sim 150{ }^{\circ} \mathrm{C}$. Glass transition temperature $\left(T_{\mathrm{g}}\right)$ was determined based on the automatic mode of TA Universal Analysis software.

\section{Synthesis of $\mathrm{AB}_{2}-\mathrm{R}$ monomers}

S1 linker
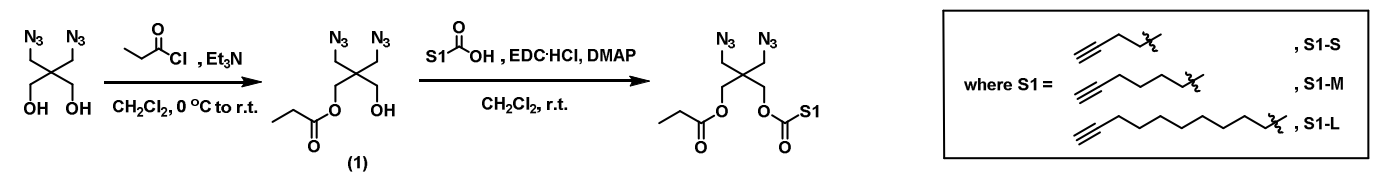

S2 linker
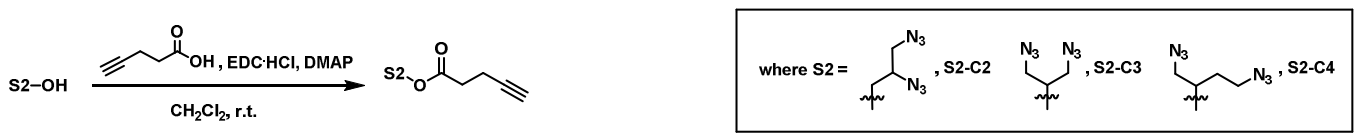

R group
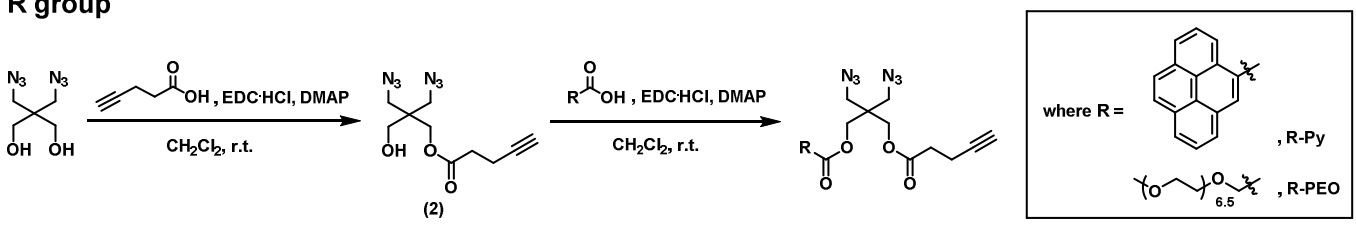

Scheme S1. Synthetic procedures of $\mathrm{AB}_{2}-\mathrm{R}$ monomers. 


\section{Synthesis of 3-azido-2-(azidomethyl)-2-(hydroxymethyl)propyl propionate}

(1). To a dried $500 \mathrm{~mL}$ round bottomed flask, 2,2-bis(azidomethyl)propane-1,3-diol (17.2 g, $92.1 \mathrm{mmol})$, triethylamine $(18.6 \mathrm{~g}, 184.2 \mathrm{mmol})$ and dried methylene chloride (300 mL) were added. The flask was immersed in a thermostatic ice bath at $0{ }^{\circ} \mathrm{C}$ and the solution was stirred for 10 min before dropwise addition of 0.9 equiv. of propionyl chloride $(7.7 \mathrm{~g}, 82.9 \mathrm{mmol})$ through a syringe pump in 12 hours. The reaction was then allowed warming to room temperature and being stirred for additional 12 hours before washed with $300 \mathrm{~mL}$ brine three times. The organic solution was dried overnight using anhydrous $\mathrm{MgSO}_{4}$ before removing the solvent under reduced pressure. The final product was purified via silica column chromatography with (hexanes/diethyl ether, 2:1 v/v) as the spreading solvent, yielding $\mathbf{1}$ as a pale yellow liquid (11.6 g, 52\% yield). ${ }^{1} \mathrm{H}$ NMR (in $\mathrm{CDCl}_{3}, \delta$, ppm): 1.15-1.19 (t, 3H), 2.11-2.14 (t, 1H), 2.37-2.42 (q, 2H), 3.37-3.44 (dd, 4H), 3.48-3.50 (d, 2H), $4.06(\mathrm{~s}, 2 \mathrm{H})$.

\section{General procedures for synthesizing $\mathrm{AB}_{2}-\mathrm{R}$ monomers with varied $\mathrm{S1}$ linker}

lengths. To a dried $100 \mathrm{~mL}$ round-bottom flask was added sequentially with compound 1 (2.9 g, $12.1 \mathrm{mmol}), 1.15$ equiv. of alkynoic acid (S1-COOH) (14.5 mmol), $\mathrm{EDC} \cdot \mathrm{HCl}(5.6 \mathrm{~g}, 29.0 \mathrm{mmol})$, dry methylene chloride $(50 \mathrm{~mL})$ and DMAP (591.5 $\mathrm{mg}, 4.8 \mathrm{mmol}$ ). The reaction mixture was allowed to be stirred at room temperature overnight before dilution with another $50 \mathrm{Ml}$ methylene chloride, the reaction mixture was then washed with water $(2 \times 100 \mathrm{~mL})$ and brine $(100 \mathrm{~mL})$, and dried over $\mathrm{MgSO}_{4}$. The solvent was evaporated, and the remaining residual was 
purified by silica gel chromatography (hexanes/diethyl ether, 3:1 v/v).

\section{3-Azido-2-(azidomethyl)-2-((propionyloxy)methyl)propyl pent-4-ynoate}

(S1-S). Colorless liquid, 3.7 g, $94 \%$ yield. ${ }^{1} \mathrm{H}$ NMR (in $\mathrm{CDCl}_{3}, \delta$, ppm): 1.12-1.17 (t, $3 \mathrm{H}), 1.99-2.01(\mathrm{t}, 1 \mathrm{H}), 2.33-2.40(\mathrm{q}, 2 \mathrm{H}), 2.49-2.54(\mathrm{~m}, 2 \mathrm{H}), 2.57-2.61(\mathrm{~m}, 2 \mathrm{H}), 3.43$ (s, 4H), 4.03 (s, 2H), 4.07 (s, 2H).

3-Azido-2-(azidomethyl)-2-((propionyloxy)methyl)propyl hept-6-ynoate (S1-M). Colorless liquid, 3.6 g, $84 \%$ yield. ${ }^{1} \mathrm{H}$ NMR (in $\mathrm{CDCl}_{3}, \delta$, ppm): 1.13-1.17 (t, $3 \mathrm{H}), 1.53-1.60$ (quint, $2 \mathrm{H}$ ), 1.72-1.79 (quint, $2 \mathrm{H}), 1.95-1.97(\mathrm{t}, 1 \mathrm{H}), 2.20-2.24(\mathrm{td}, 2 \mathrm{H})$, 2.34-2.39 (m, 4H), $3.42(\mathrm{~s}, 4 \mathrm{H}), 4.03(\mathrm{~s}, 4 \mathrm{H})$.

\section{3-Azido-2-(azidomethyl)-2-((propionyloxy)methyl)propyl undec-10-ynoate} (S1-L). Colorless liquid, 4.7 g, $96 \%$ yield. ${ }^{1} \mathrm{H}$ NMR (in $\mathrm{CDCl}_{3}, \delta$, ppm): 1.13-1.17 (t, $3 \mathrm{H}), 1.26-1.43$ (m, 8H), 1.48-1.55 (quint, 2H), 1.58-1.66 (quint, 2H), 1.92-1.94 (t, 1H), 2.15-2.20 (td, 2H), 2.31-2.34 (t, 2H), 2.34-2.39 (q, 2H), $3.42(\mathrm{~s}, 4 \mathrm{H}), 4.02(\mathrm{~s}, 4 \mathrm{H})$.

General procedures for synthesizing $\mathrm{AB}_{2}-\mathrm{R}$ monomers with varied S2 linker lengths. To a dried $100 \mathrm{~mL}$ round-bottom flask was added sequentially with alcohol with diazido units (S2-OH) (17.4 mmol), 1.15 equiv. of pent-4-ynoic acid (1.96 g, $20.0 \mathrm{mmol}), \mathrm{EDC} \cdot \mathrm{HCl}(7.7 \mathrm{~g}, 40.0 \mathrm{mmol})$, dry methylene chloride $(50 \mathrm{~mL})$ and DMAP (814.7 mg, $6.7 \mathrm{mmol})$. The reaction mixture was allowed to be stirred at room temperature overnight before dilution with another $50 \mathrm{~mL}$ methylene chloride, the reaction mixture was then washed with water $(2 \times 100 \mathrm{~mL})$ and brine $(100 \mathrm{~mL})$, and dried over $\mathrm{MgSO}_{4}$. The solvent was evaporated, and the remaining residual was purified by silica gel chromatography (hexanes/diethyl ether, 3:1 v/v). 
2,3-Diazidopropyl pent-4-ynoate (S2-C2). Pale yellow liquid, 3.6 g, $92 \%$ yield. ${ }^{1} \mathrm{H}$ NMR (in $\left.\mathrm{CDCl}_{3}, \delta, \mathrm{ppm}\right):$ 1.98-2.01 (t, $\left.1 \mathrm{H}\right), 2.50-2.56(\mathrm{~m}, 2 \mathrm{H}), 2.60-2.64(\mathrm{~m}, 2 \mathrm{H})$, 3.37-3.50 (m, 2H), 3.76-3.83 (m, 1H), 4.17-4.30 (m, 2H).

1,3-Diazidopropan-2-yl pent-4-ynoate (S2-C3). Colorless liquid, 3.4 g, 89\% yield. ${ }^{1} \mathrm{H}$ NMR (in $\mathrm{CDCl}_{3}, \delta$, ppm): 1.99-2.01 (t, $\left.1 \mathrm{H}\right), 2.51-2.56(\mathrm{~m}, 2 \mathrm{H}), 2.61-2.66$ (m, 2H), 3.45-3.54 (dd, 4H), 5.06-5.13 (quint, 1H).

1,4-Diazidobutan-2-yl pent-4-ynoate (S2-C4). Pale yellow liquid, 3.5 g, 85\% yield. ${ }^{1} \mathrm{H}$ NMR (in $\mathrm{CDCl}_{3}, \delta$, ppm): 1.80-1.99 (m, 2H), 1.99-2.01 (t, 1H), 2.50-2.54 $(\mathrm{m}, 2 \mathrm{H}), 2.57-2.62(\mathrm{~m}, 2 \mathrm{H}), 3.32-3.52(\mathrm{~m}, 4 \mathrm{H}), 5.10-5.16(\mathrm{~m}, 1 \mathrm{H})$.

\section{Synthesis of 3-azido-2-(azidomethyl)-2-(hydroxymethyl)propyl}

pent-4-ynoate (2). To a dried $500 \mathrm{~mL}$ round-bottom flask was added sequentially with 2,2-bis(azidomethyl)propane-1,3-diol (12.5 g, $67.1 \mathrm{mmol}), 0.7$ equiv. of pent-4-ynoic acid (4.6 g, 47.0 mmol), EDC· $\mathrm{HCl}(21.9 \mathrm{~g}, 114.1 \mathrm{mmol})$, dry methylene chloride (200 mL) and DMAP (2.3 g, $19.0 \mathrm{mmol})$. The reaction mixture was allowed to be stirred at room temperature overnight before dilution with another $200 \mathrm{~mL}$ methylene chloride, the reaction mixture was then washed with water $(2 \times 400 \mathrm{~mL})$ and brine (400 mL), and dried over $\mathrm{MgSO}_{4}$. The solvent was evaporated, and the remaining residual was purified by silica gel chromatography (hexanes/diethyl ether, 2:1 v/v) to give a pale yellow liquid (6.2 g, 50\% yield). ${ }^{1} \mathrm{H} \mathrm{NMR}$ (in $\mathrm{CDCl}_{3}, \delta, \mathrm{ppm}$ ): 2.00-2.02 (t, $1 \mathrm{H}), 2.12-2.16(\mathrm{t}, 1 \mathrm{H}), 2.50-2.55(\mathrm{~m}, 2 \mathrm{H}), 2.59-2.63(\mathrm{~m}, 2 \mathrm{H}), 3.38-3.45$ (dd, 4H), 3.49-3.53 (d, 2H), $4.10(\mathrm{~s}, 2 \mathrm{H})$.

General procedures for synthesizing $\mathrm{AB}_{2}-\mathrm{R}$ monomers with varied $\mathrm{R}$ 
dangling groups. To a dried $100 \mathrm{~mL}$ round-bottom flask was added sequentially with compound 2 ( $3.0 \mathrm{~g}, 11.3 \mathrm{mmol}), 1.15$ equiv. of R-COOH $(13.0 \mathrm{mmol}), \mathrm{EDC} \cdot \mathrm{HCl}(5.0$ g, $26.0 \mathrm{mmol})$, dry methylene chloride $(50 \mathrm{~mL})$ and DMAP (529.5 mg, $4.3 \mathrm{mmol})$. The reaction mixture was allowed to be stirred at room temperature overnight before dilution with another $50 \mathrm{~mL}$ methylene chloride, the reaction mixture was then washed with water $(2 \times 100 \mathrm{~mL})$ and brine $(100 \mathrm{~mL})$, and dried over $\mathrm{MgSO}_{4}$. The solvent was evaporated, and the remaining residual was purified by silica gel chromatography (hexanes/diethyl ether, 3:1 v/v for R-Py and 2:3 for R-PEO).

\section{3-Azido-2-(azidomethyl)-2-((pent-4-ynoyloxy)methyl)propylpyrene-1-carbox}

ylate (R-Py). Yellow solid, $4.6 \mathrm{~g}, 82 \%$ yield. ${ }^{1} \mathrm{H} \mathrm{NMR}$ (in $\mathrm{CDCl}_{3}, \delta$, ppm): 1.97-1.99 (t, 1H), 2.51-2.55 (m, 2H), 2.60-2.65 (m, 2H), $3.63(\mathrm{~s}, 4 \mathrm{H}), 4.28(\mathrm{~s}, 2 \mathrm{H}), 4.48(\mathrm{~s}, 2 \mathrm{H})$, 8.07-8.58 (m, 9H).

3-azido-2-(azidomethyl)-2-((methoxypoly(ethylene glycol)acetoxy)methyl) propyl pent-4-ynoate (R-PEO). Colorless liquid, $5.5 \mathrm{~g}$, $79 \%$ yield. ${ }^{1} \mathrm{H}$ NMR (in $\left.\mathrm{CDCl}_{3}, \delta, \mathrm{ppm}\right): 2.00-2.02(\mathrm{t}, 1 \mathrm{H}), 2.49-2.54(\mathrm{~m}, 2 \mathrm{H}), 2.57-2.61(\mathrm{~m}, 2 \mathrm{H}), 3.38(\mathrm{~s}, 3 \mathrm{H})$, $3.45(\mathrm{~s}, 4 \mathrm{H}), 3.53-3.74(\mathrm{~m}, 26 \mathrm{H}), 4.07(\mathrm{~s}, 2 \mathrm{H}), 4.11(\mathrm{~s}, 2 \mathrm{H}), 4.18(\mathrm{~s}, 2 \mathrm{H})$. 
A

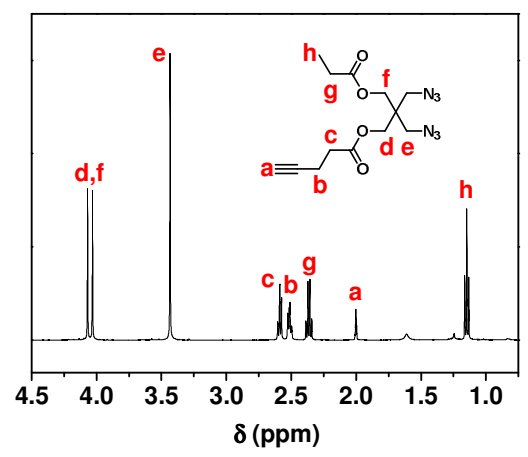

C



$\mathbf{E}$

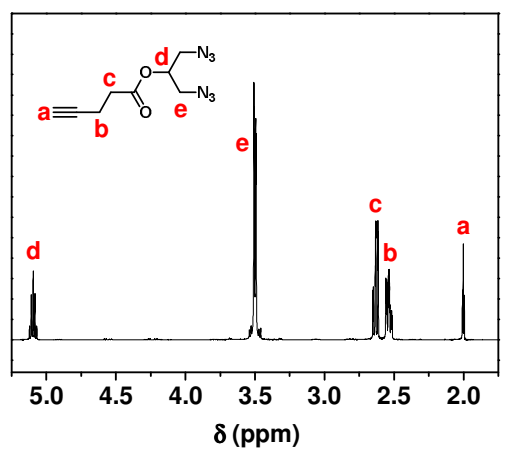

G

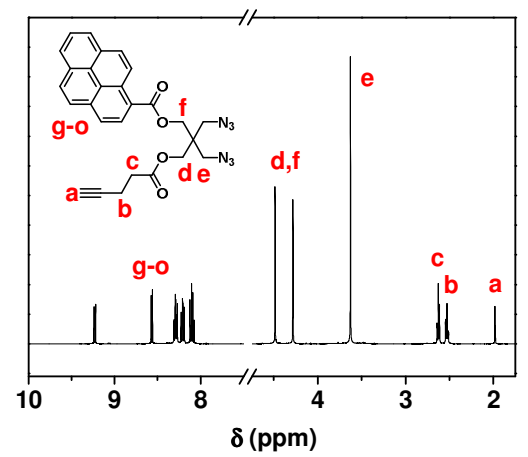

B



D

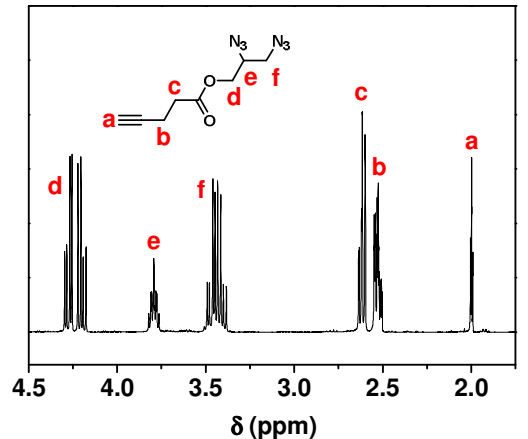

$\mathbf{F}$

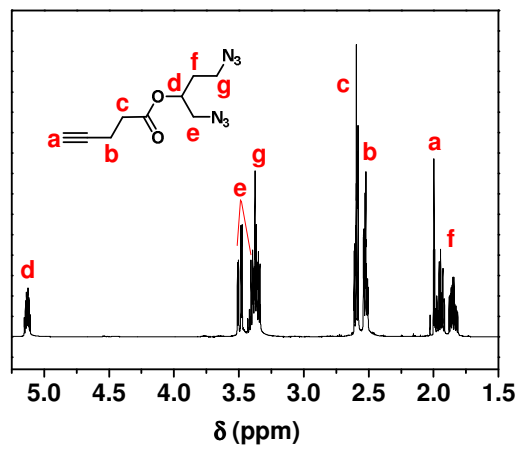

H

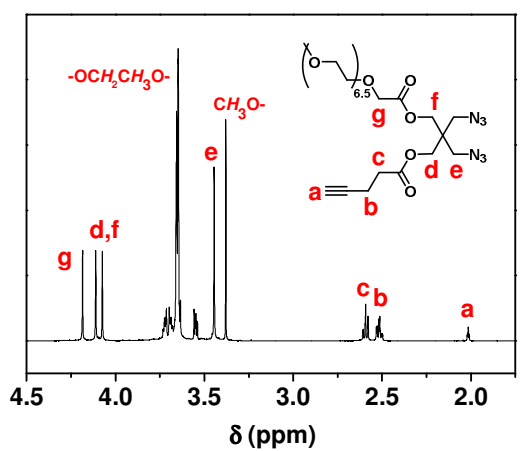

Figure S1. ${ }^{1} \mathrm{H}$ NMR spectra of $\mathrm{AB}_{2}-\mathrm{R}$ monomers in $\mathrm{CDCl}_{3}$. 
The polymerization of $\mathrm{AB}_{2}-\mathrm{R}$ monomer in one pot was at fixed molar ratios of $\left[\mathrm{AB}_{2}-\mathrm{R}\right]_{0}:\left[\mathrm{CuSO}_{4} \cdot 5 \mathrm{H}_{2} \mathrm{O}\right]_{0}:[\text { ascorbic acid }]_{0}=100: 1: 5$. Typical procedures are described below using S1-S as an example. S1-S (500.0 mg, $1.6 \mathrm{mmol}), \mathrm{CuSO}_{4} \cdot 5 \mathrm{H}_{2} \mathrm{O}$ (3.9 mg, $15.5 \mu \mathrm{mol})$ and $3.2 \mathrm{~mL} \mathrm{DMF}\left([\mathrm{S} 1-\mathrm{S}]_{0}=0.5 \mathrm{~mol} \mathrm{~L}^{-1}\right)$ were charged in a $10 \mathrm{~mL}$ schlenk flask. This flask was capped with rubber septa and bubbled with nitrogen gas for $40 \mathrm{~min}$, followed by quickly adding ascorbic acid $(13.7 \mathrm{mg}, 77.6 \mu \mathrm{mol})$ into the flask. The flask was then immersed in a thermostatic oil bath at $45^{\circ} \mathrm{C}$ for initiating the polymerization. Samples were withdrawn using deoxygenated syringes at each predetermined time interval and were quenched by exposure to air and the addition of two equivalents of PMDETA. Each sample was split into two portions: one was diluted by THF or DMF for SEC measurement, and another was diluted by DMSO- $d_{6}$ for the assessment of monomer conversion by ${ }^{1} \mathrm{H}$ NMR spectroscopy. The polymerization was stopped at nearly full (i.e. > 95\%) monomer conversion and diluted with $10 \mathrm{~mL} \mathrm{CH} \mathrm{Cl}_{2}$, and $\mathrm{Cu}$ catalyst was removed by adding two equivalents of PMDETA followed by passing through a flash basic alumina column, ${ }^{11}$ the catalyst-free hyperbranched polymers were then purified by precipitating into large amount of methanol (or diethyl ether for $\mathrm{HBP}(\mathrm{R}-\mathrm{PEO})$ specifically) three times. The final product was dried under vacuum to a constant mass.

\section{General procedures for $\mathrm{CuAAC}$ polymerization of $\mathrm{AB}_{2}-\mathrm{R}$ in sequential} addition of monomer. In all cases, the first batch of polymerization was conducted at molar ratios of $\left[\mathrm{AB}_{2}-\mathrm{R}\right]_{0}:\left[\mathrm{CuSO}_{4} \cdot 5 \mathrm{H}_{2} \mathrm{O}\right]_{0}:[\text { ascorbic acid }]_{0}=50: 1: 5$ in DMF with $\left[\mathrm{AB}_{2}-\mathrm{R}\right]_{0}=0.5 \mathrm{~mol} \mathrm{~L}{ }^{-1}$. After reaching a complete monomer conversion $(>95 \%)$, a 
$2^{\text {nd }}$ batch of deoxygenated $\mathrm{AB}_{2}-\mathrm{R}$ monomer (another 50 equiv. to $\mathrm{Cu}$ ) in $\mathrm{DMF}(0.5$ mol $\mathrm{L}^{-1}$ of monomer) was added into the reaction system. Samples were taken using deoxygenated syringes right before adding the second batch of monomer and diluted with THF or DMF for SEC measurement. The final hyperbranched polymers were subjected to the same purification steps as above.
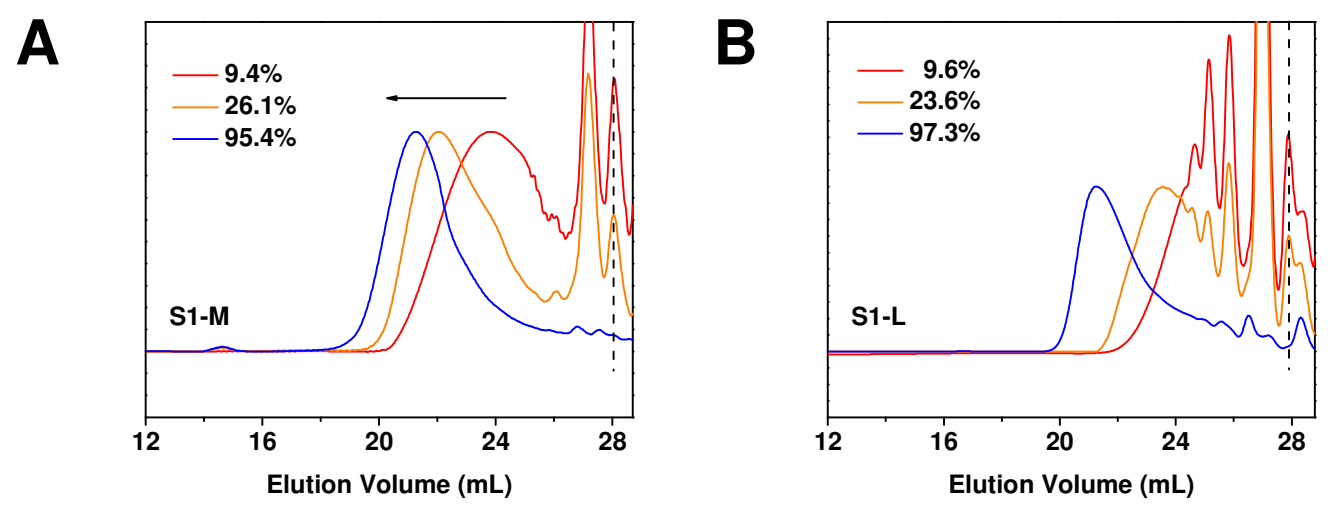

Figure S2. Overlaid SEC curves (RI signal in THF) of (A) HBP(S1-M) and (B) $\operatorname{HBP}(\mathrm{S} 1-\mathrm{L})$ polymers at various conversions, the dashed lines indicate the linear dimer peak for reference. Reaction condition: $[\mathrm{S} 1]_{0}:\left[\mathrm{CuSO}_{4} \cdot 5 \mathrm{H}_{2} \mathrm{O}\right]_{0}:[$ ascorbic $\operatorname{acid}]_{0}=100: 1: 5$ in DMF at $45^{\circ} \mathrm{C},[\mathrm{S} 1]_{0}=0.5 \mathrm{~mol} \mathrm{~L}^{-1}$.

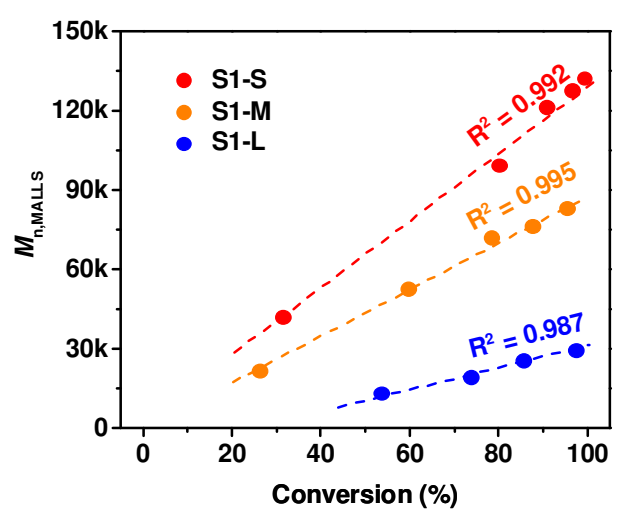

Figure S3. Evolution of number-average molecular weights $\left(M_{\mathrm{n}, \mathrm{MALLS}}\right)$ from the one-pot polymerizations of $\mathrm{AB}_{2}-\mathrm{R}$ monomers S1-S, S1-M and S1-L, determined 
by SEC with a MALLS detector in THF.

A

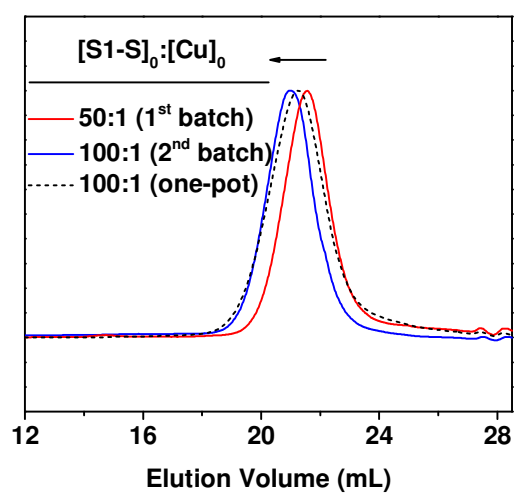

C

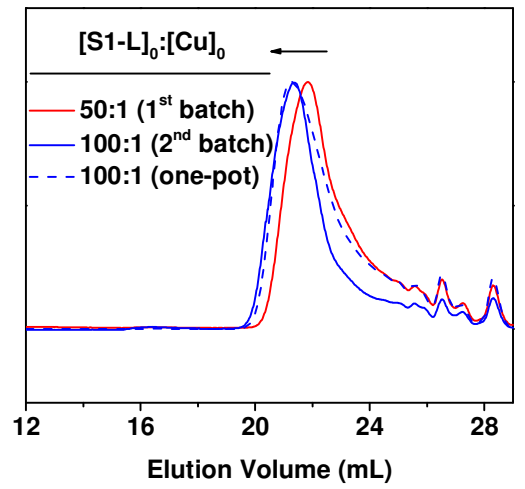

B
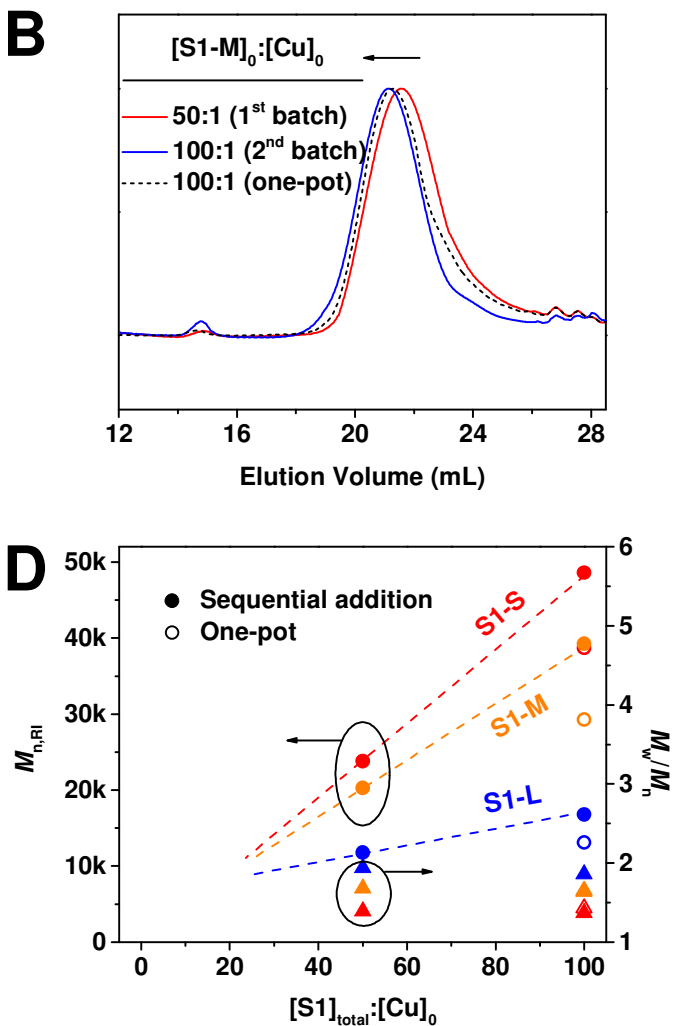

Figure S4. SEC traces (solid line, RI signal in THF) of hyperbranched polymers produced by batchwise polymerization of (A) S1-S, (B) S1-M and (C) S1-L with initial condition $[\mathrm{S} 1]:\left[\mathrm{CuSO}_{4} \cdot 5 \mathrm{H}_{2} \mathrm{O}\right]_{0}:[\text { ascorbic acid }]_{0}=50: 1: 5$ in DMF at $45^{\circ} \mathrm{C}$, the second 50 equiv. monomer was added at $>98 \%$ monomer conversion of previous batch without any purification, $\left[\mathrm{AB}_{2}\right]_{0}$ was kept at a concentration of 0.5 mol $\mathrm{L}^{-1}$ during the whole reaction; one-pot polymerization at condition $[\mathrm{S} 1]_{0}:\left[\mathrm{CuSO}_{4} \cdot 5 \mathrm{H}_{2} \mathrm{O}\right]_{0}:[\text { ascorbic acid }]_{0}=100: 1: 5$ in DMF at $45^{\circ} \mathrm{C}$ (dashed line) is shown as comparison. (D) The $M_{\mathrm{n}, \mathrm{RI}}$ and $M_{\mathrm{w}} / M_{\mathrm{n}}$ as a function of $[\mathrm{S} 1]_{\mathrm{total}}:[\mathrm{Cu}]_{0}$. 
Linear dimer of S1-S

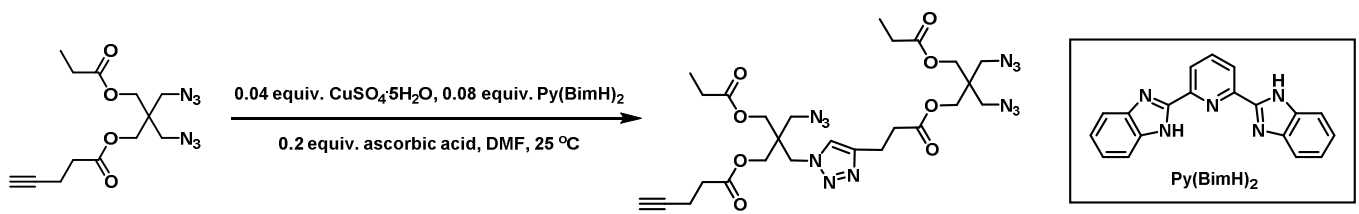

Cyclic S1-L

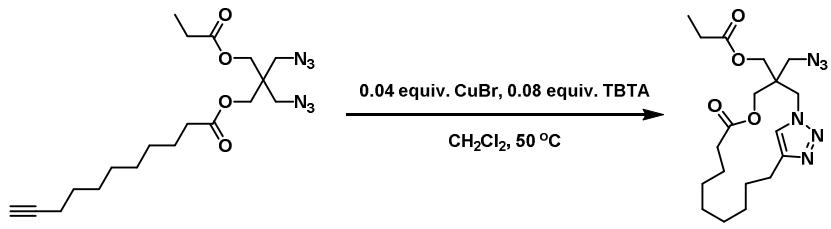

Scheme S2. Synthetic routes of two SEC standards: linear dimer of S1-S and cyclic S1-L.

\section{Synthesis of 3-azido-2-((4-(3-(3-azido-2-(azidomethyl)-2-((propionyloxy)} methyl)propoxy)-3-oxopropyl)-1H-1,2,3-triazol-1-yl)methyl)-2-((propionyloxy)m ethyl)propyl pent-4-ynoate (linear dimer of S1-S). To simplify the procedures, the linear dimer of S1-S was synthesized and separated through CuAAC polymerization method with optimized condition. Here, 0.04 equiv. $\mathrm{CuSO}_{4} \cdot 5 \mathrm{H}_{2} \mathrm{O}$ and excessive ascorbic acid were used to generate $\mathrm{Cu}^{\mathrm{I}}$ catalyst, while an additional 0.08 equiv. of ligand $\mathrm{Py}(\mathrm{BimH})_{2}$ was applied to yield monotriazole as the major product, according to Finn's work. ${ }^{12} \mathrm{~S} 1-\mathrm{S}(200.0 \mathrm{mg}, 620.8 \mu \mathrm{mol}), \mathrm{CuSO}_{4} \cdot 5 \mathrm{H}_{2} \mathrm{O}(6.2 \mathrm{mg}, 24.8 \mu \mathrm{mol})$, $\mathrm{Py}(\mathrm{BimH})_{2}(15.4 \mathrm{mg}, 49.6 \mu \mathrm{mol})$ and $6.2 \mathrm{~mL} \mathrm{DMF}\left([\mathrm{S} 1-\mathrm{S}]_{0}=0.1 \mathrm{~mol} \mathrm{~L}^{-1}\right)$ were charged in a $10 \mathrm{~mL}$ schlenk flask. This flask was capped with rubber septa and bubbled with nitrogen gas for $40 \mathrm{~min}$, followed by quickly adding ascorbic acid (21.9 $\mathrm{mg}, 124.2 \mu \mathrm{mol})$ into the flask. The flask was then immersed in a thermostatic oil bath at room temperature. The bi-phase reaction was stopped after 24 hours with nearly $10 \%$ monomer conversion, yielding majority of linear dimer with slight contamination of 
higher molecular weight oligomeric species. The mixture was diluted with $15 \mathrm{~mL}$ $\mathrm{CH}_{2} \mathrm{Cl}_{2}$, and $\left.\mathrm{Cu} \cdot \mathrm{Py}(\mathrm{BimH})_{2}\right]_{2}$ catalyst was removed by passing through a flash basic alumina column. After adding another $50 \mathrm{~mL} \mathrm{CH}_{2} \mathrm{Cl}_{2}$, the catalyst-free solution was washed with water $(2 \times 100 \mathrm{~mL})$ and brine $(100 \mathrm{~mL})$ to remove DMF, and dried over $\mathrm{MgSO}_{4}$. The solvent was evaporated, and the remaining residual was purified by silica gel chromatography (hexanes/diethyl ether, $3: 1$ to $1: 1 \mathrm{v} / \mathrm{v}$ ), yielding linear dimer of $\mathrm{S} 1-\mathrm{S}$ as a yellow oil $(9.8 \mathrm{mg}, 5 \%$ yield $)$, the unreacted monomer was recovered. ${ }^{1} \mathrm{H}$ NMR (in $\left.\mathrm{CDCl}_{3}, \delta, \mathrm{ppm}\right)$ : 1.11-1.19 (m, 6H), 2.01-2.03 (t, 1H), 2.31-2.41 (m, 4H), 2.47-2.55 (m, 2H), 2.55-2.64 (m, 2H), 2.75-2.80 (t, 2H), 3.00-3.06 (t, 2H), $3.39(\mathrm{~s}$, 4H), $3.41(\mathrm{~s}, 2 \mathrm{H}), 3.96-4.05(\mathrm{~m}, 8 \mathrm{H}), 4.41(\mathrm{~s}, 2 \mathrm{H}), 7.39(\mathrm{~s}, 1 \mathrm{H})$.

\section{Synthesis of (Z)-(3-(azidomethyl)-6-oxo-1 ${ }^{1} H-5-0 \times a-1(1,4)$-triazolacyclo-} tetradecaphane-3-yl)methyl propionate (cyclic S1-L). The macrocyclization of S1-L monomer adopted an optimized condition reported by James et al.. ${ }^{13} \mathrm{CuBr}$ and tris((1-benzyl-1H-1,2,3-triazolyl)methyl)amine (TBTA) were used as catalyst and ligand, separately. S1-L (200.0 mg, $492.3 \mu \mathrm{mol})$, TBTA (20.9 mg, $39.4 \mu \mathrm{mol})$ were charged in a $50 \mathrm{~mL}$ schlenk flask equipped with a reflux condenser. This system was capped with rubber septa and bubbled with nitrogen gas for $20 \mathrm{~min}$, followed by charging $24.6 \mathrm{~mL}$ deoxygenated $\mathrm{CH}_{2} \mathrm{Cl}_{2}\left([\mathrm{~S} 1-\mathrm{L}]_{0}=0.02 \mathrm{~mol} \mathrm{~L}{ }^{-1}\right)$. After adding $\mathrm{CuBr}$ (2.8 mg, $19.7 \mu \mathrm{mol}$ ), the flask was then immersed in a thermostatic oil bath at $50{ }^{\circ} \mathrm{C}$. The reaction was ceased after 48 hours, yielding majority of cyclic monomer with slight contamination of oligomeric species. The reaction mixture was directly passed through a flash basic alumina column. The solvent was then evaporated under reduced 
pressure, and the remaining residual was purified by silica gel chromatography (hexanes/diethyl ether, 3:1 to 2:1 v/v), yielding cyclic S1-L as a white solid (112.6 mg, $56 \%$ yield). ${ }^{1} \mathrm{H}$ NMR (in $\mathrm{CDCl}_{3}, \delta, \mathrm{ppm}$ ): 1.14-1.20 (t, 3H), 1.20-1.79 (m, 12H), 2.28-2.44 (m, 4H), 2.74-2.86 (m, 2H), 3.47-3.52 (d, 2H), 3.55-3.76 (dd, 2H), 4.14-4.22 (dd, 2H), 4.28-4.47 (dd, 2H), $7.28(\mathrm{~s}, 1 \mathrm{H})$.
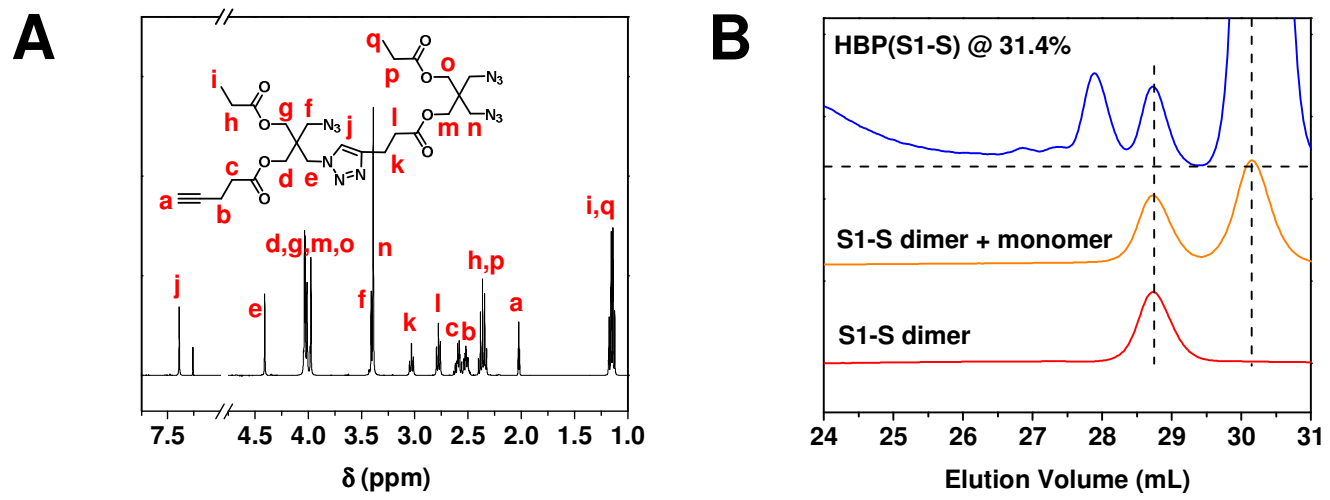

Figure S5. (A) ${ }^{1} \mathrm{H}$ NMR spectrum of linear dimer of $\mathrm{S} 1-\mathrm{S}$ in $\mathrm{CDCl}_{3}$, and (B) comparison between the SEC curves (RI signal in THF) of pure dimer of S1-S (red), a mixture with monomer S1-S (orange), and the sample withdrawn at $31.4 \%$ monomer conversion in one-pot polymerization of S1-S (blue).
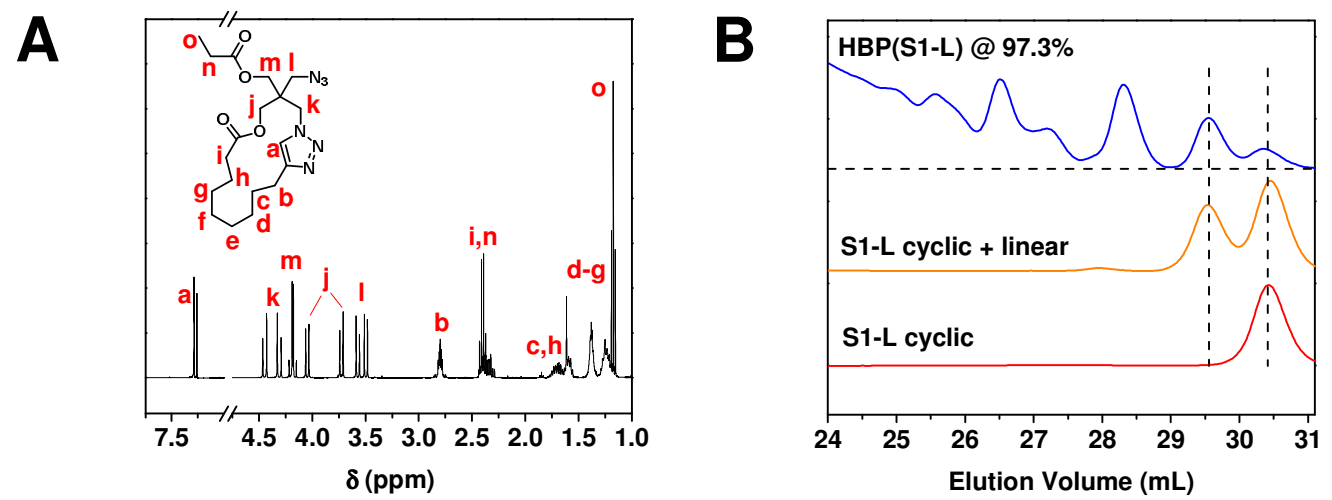

Figure S6. (A) ${ }^{1} \mathrm{H}$ NMR spectrum of cyclic $\mathrm{S} 1-\mathrm{L}$ in $\mathrm{CDCl}_{3}$, and (B) comparison between SEC curves (RI signal in THF) of cyclic S1-L, a mixture with linear S1-L 
(orange), and the final sample with $97.3 \%$ monomer conversion in one-pot polymerization of S1-L (blue).
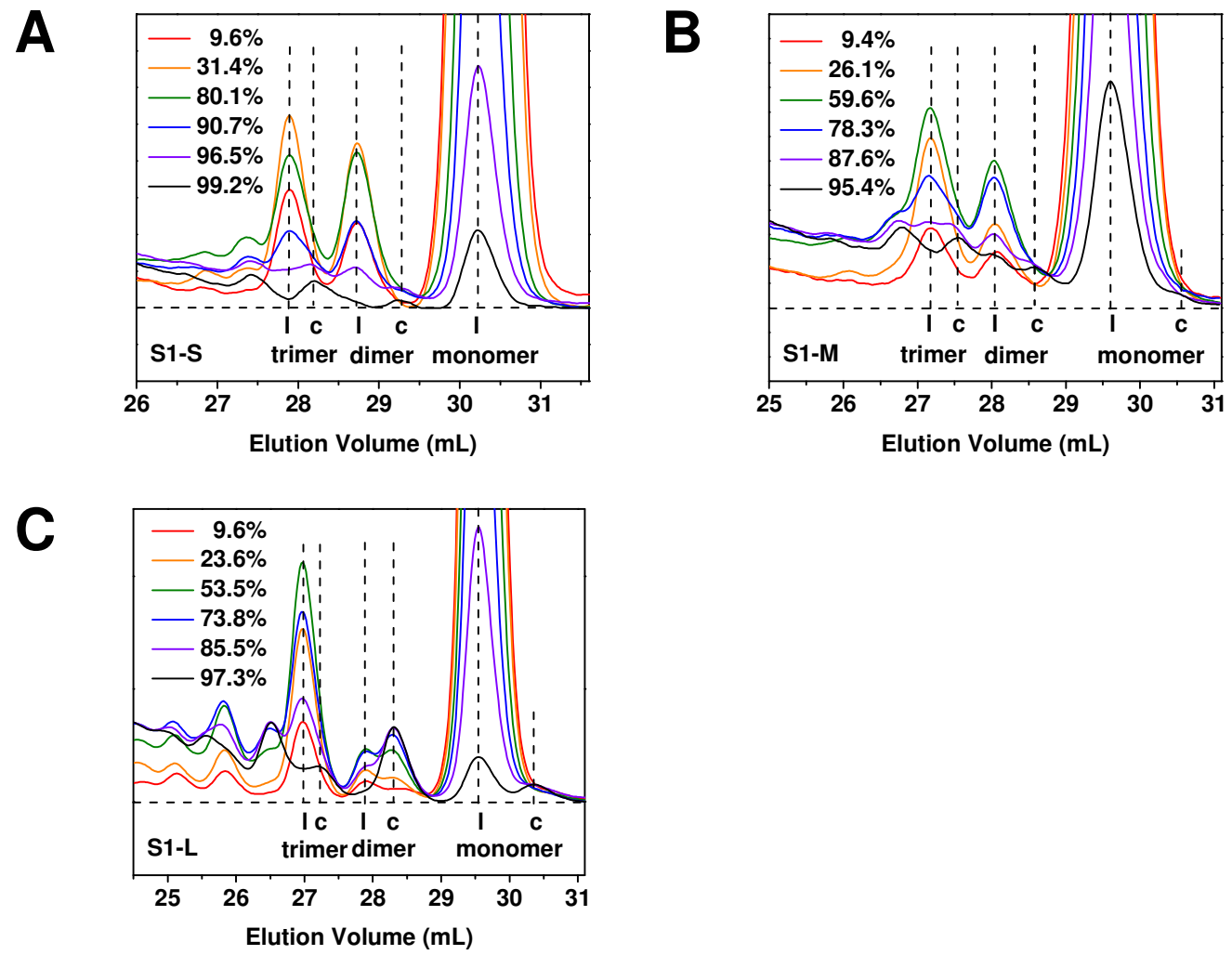

Figure S7. Zoom-in low molecular weight region of the normalized SEC traces in one-pot polymerization of (A) S1-S, (B) S1-M and (C) S1-L.

\section{General procedures for multi-peak fitting and peak integration of SEC}

curves. The fitting and peak integration procedures were carried out by using OriginPro 9. The SEC curve (RI signal) of the sample collected at 53.5\% monomer conversion from S1-L polymerization is used here as an example. Firstly, the baselines of all SEC curves were manually adjusted to 0 through Tabs: Analysis

Mathematics Simple Curve Math. The integral of the product signals (red shaded area in Figure S8A) can be checked at Gadgets Integrate and the value was 
normalized to 1 through Simple Curve Math.

It is very difficult to deconvolute the entire SEC curve due to the complexity of various peaks. Thus only part of the trace was selected to include the targeted signals of cyclic and linear monomer, dimer, trimer and some larger oligomeric species for accuracy (e.g. elution volume ranged from 25.3 to $31.0 \mathrm{~mL}$ for $\operatorname{HBP}(\mathrm{S} 1-\mathrm{L})$ samples, Figure S8B). The multiple-peak fitting was applied in the intercepted new curve using the Tabs: Peaks and Baseline Peak Analyzer tool with procedures listed below: (1) set Goal to Fit Peaks (Pro), click Next; (2) set Baseline Mode to Constant 0, click Next; (3) set Baseline Treatment to Fix Baseline Parameters, click Next; (4) manually add peaks in Find Peaks session based on previous peak attribution, click Next; (5) click Fit Control in the last page of the wizard and choose "Gaussian" as Peak Type, click OK then Fit, (6) abnormal fitted curve usually indicates some peaks do not exist (e.g. cyclic S1-L monomer cannot be fitted in Figure S8B), then redo the above fitting from step 4 and choose the best matched curve. Finally, the area for each fitted peak was obtained by using Tabs: Gadgets Integrate, equaling to the weight fraction (e.g. blue shaded area $=0.0225$ ) of $2.25 \mathrm{wt} \%$ cyclic dimer species.
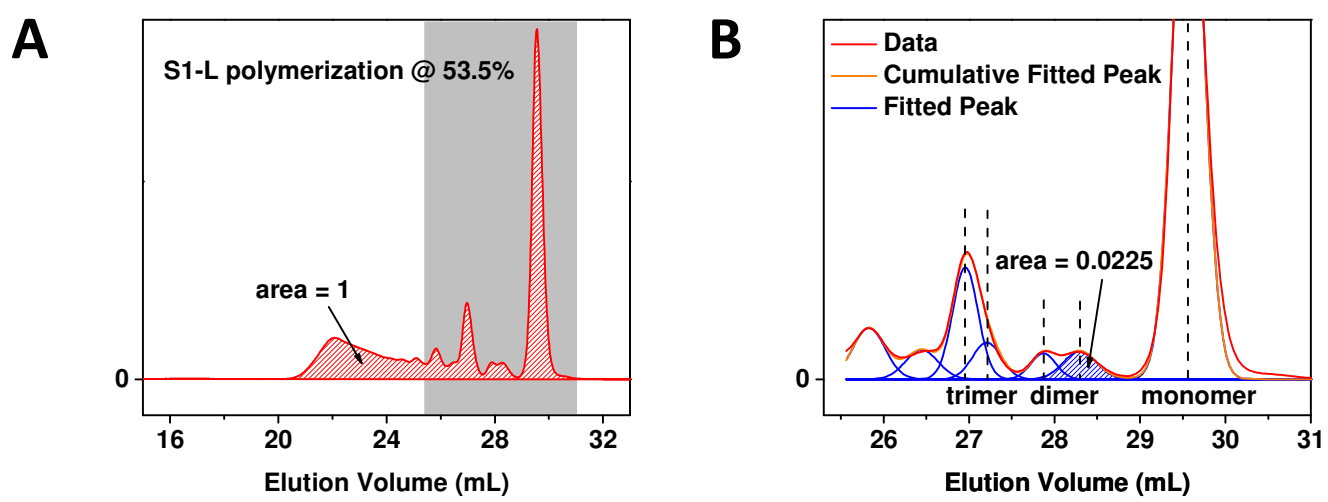

Figure S8. (A) SEC trace of $\mathrm{HBP}(\mathrm{S} 1-\mathrm{L})$ at $53.5 \%$ conversion, and (B) multi-peak S16 
fitting in the intercepted curve (grey shaded area in A) with elution volume from 25.3 to $31.0 \mathrm{~mL}$.
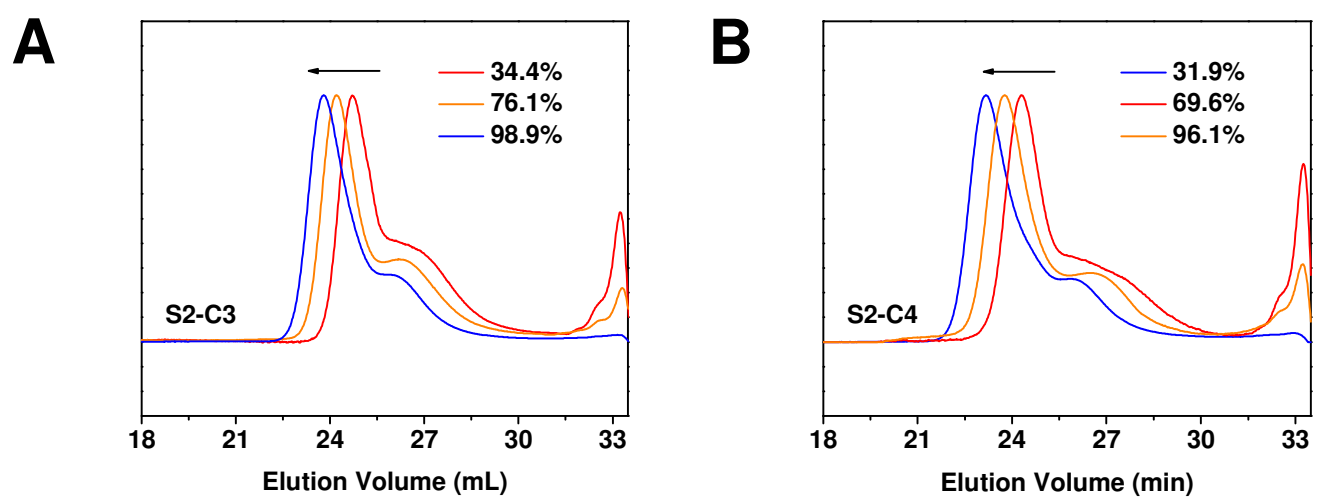

Figure S9. Stacked SEC traces (RI signal in DMF) of hyperbranched polymer from one-pot polymerization of (A) S2-C3, (B) S2-C4 monomer, at feed ratio of $[\mathrm{S} 2]_{0}:\left[\mathrm{CuSO}_{4} \cdot 5 \mathrm{H}_{2} \mathrm{O}\right]_{0}:[\text { ascorbic acid }]_{0}=100: 1: 5$ in DMF at $45{ }^{\circ} \mathrm{C}$.

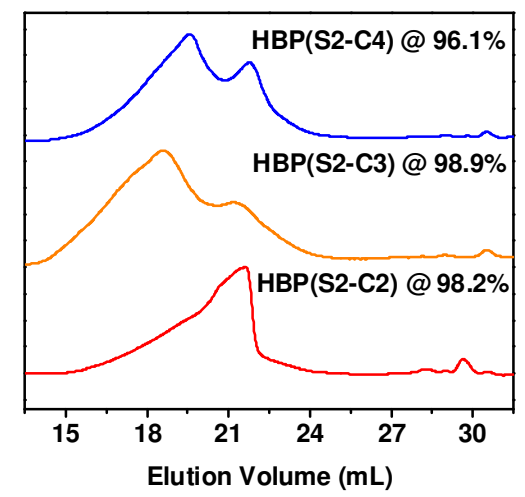

Figure S10. Stacked SEC traces (RI signal in THF) of HBP(S2-C2), HBP(S2-C3) and $\operatorname{HBP}(\mathrm{S} 2-\mathrm{C} 4)$ with conversions $>96 \%$. Due to significant polymer aggregation in THF mobile phase, the polymers showed very broad distribution with apparent $M_{\mathrm{w}} / M_{\mathrm{n}}=5.47,12.1,7.20$, respectively. 
A

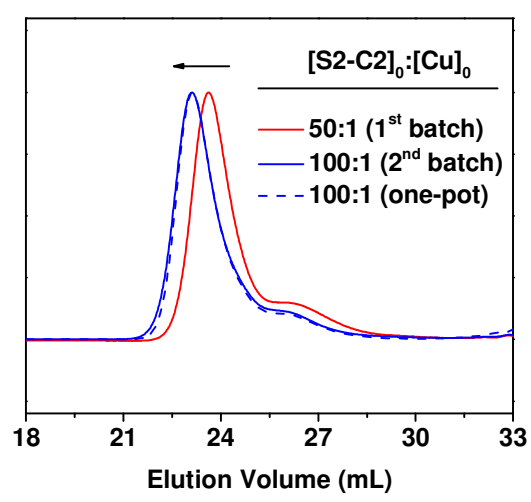

C



B
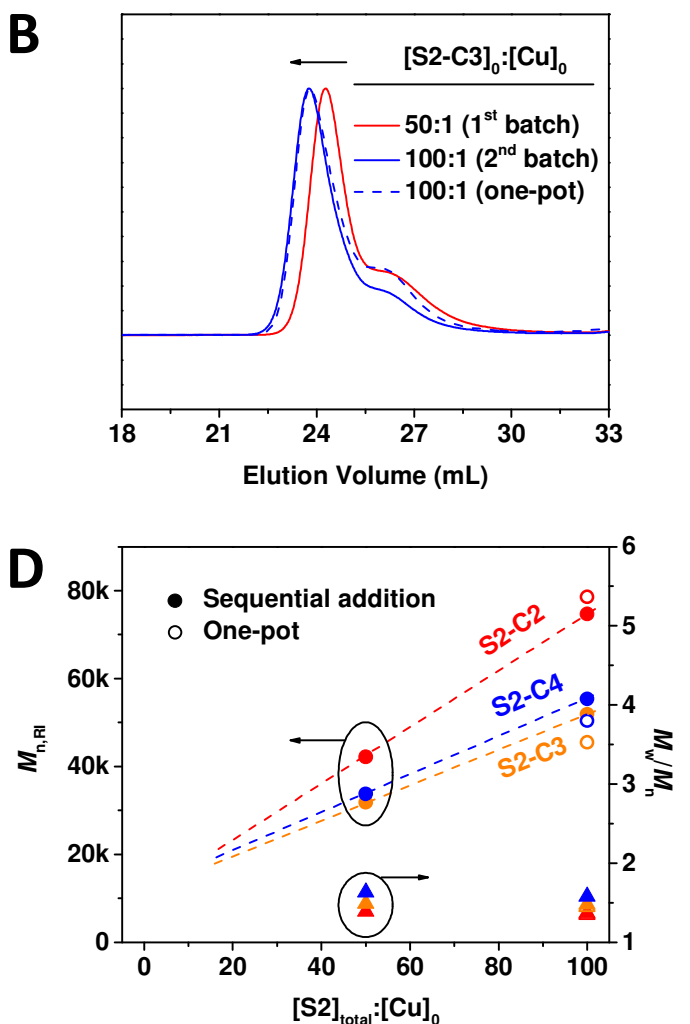

Figure S11. SEC traces (solid line, RI signal in DMF) of hyperbranched polymers produced by batchwise polymerization of (A) S2-C2, (B) S2-C3 and (C) S2-C4, the final product of one-pot polymerization is shown as comparison (dashed line). (D) The $M_{\mathrm{n}, \mathrm{RI}}$ and $M_{\mathrm{w}} / M_{\mathrm{n}}$ as a function of $[\mathrm{S} 2]_{\mathrm{total}}:[\mathrm{Cu}]_{0}$. 

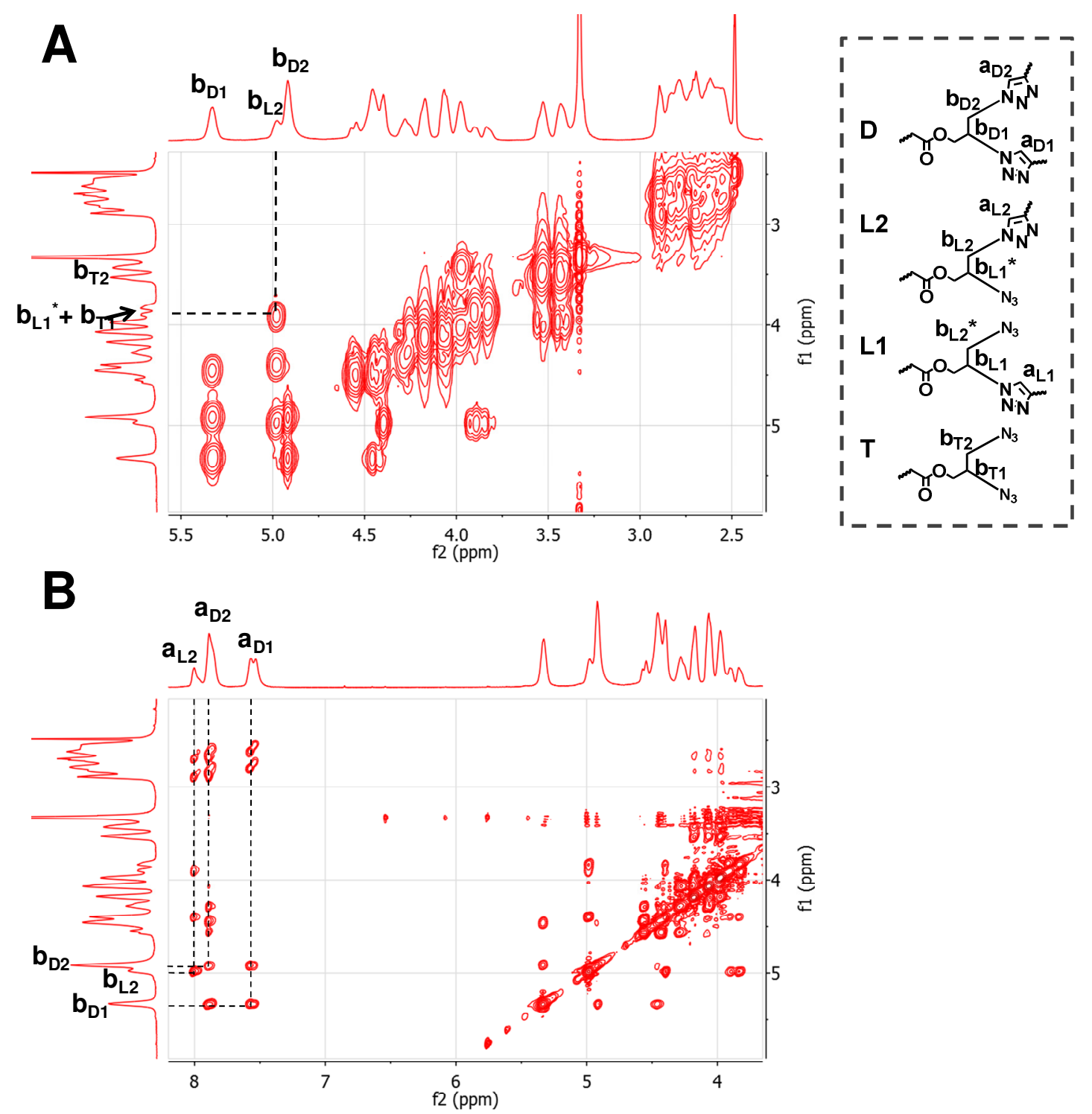

Figure S12. (A) COSY and (B) ROESY 2D NMR spectra of the HBP(S2-C2) sample prepared by one-pot method in DMSO- $d_{6}$. 


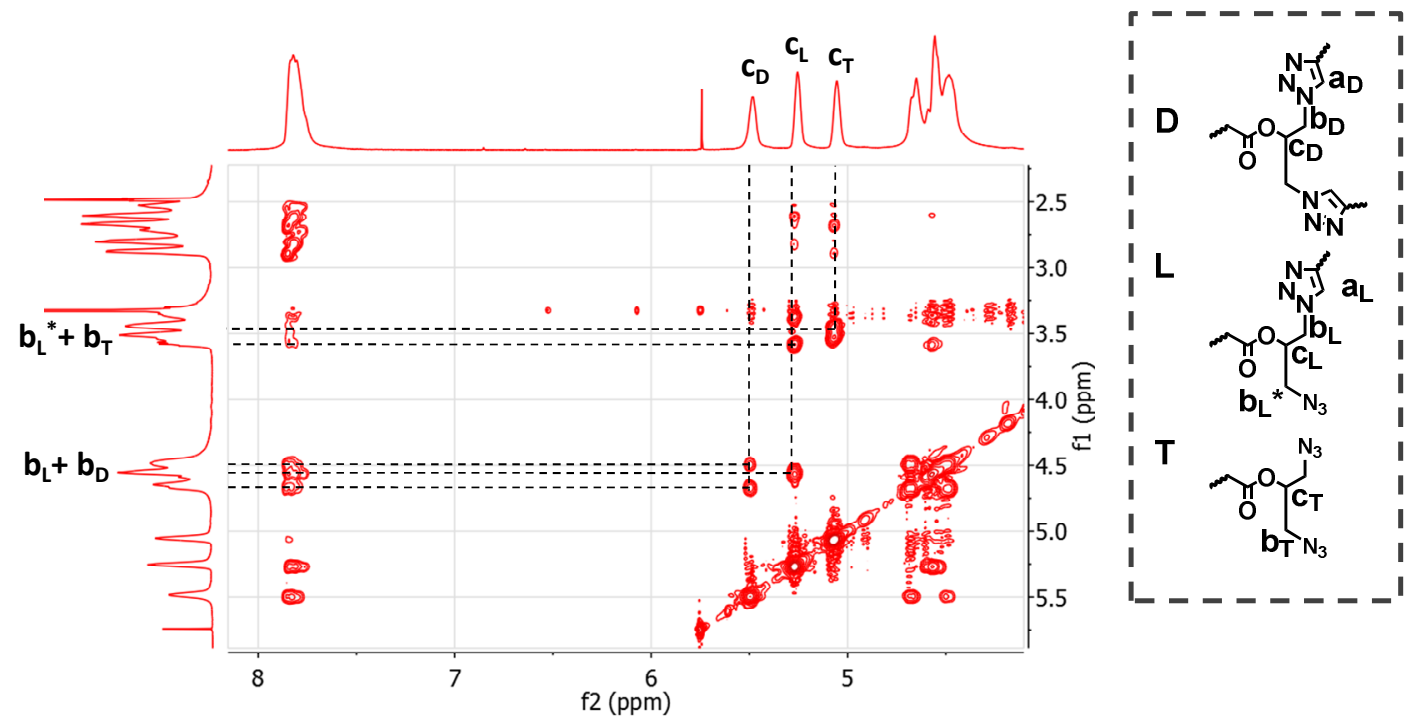

Figure S13. ROESY 2D NMR spectrum of the HBP(S2-C3) sample prepared by one-pot method in DMSO- $d_{6}$.



Figure S14. ROESY 2D NMR spectrum of the HBP(S2-C4) sample prepared by one-pot method in DMSO- $d_{6}$. 


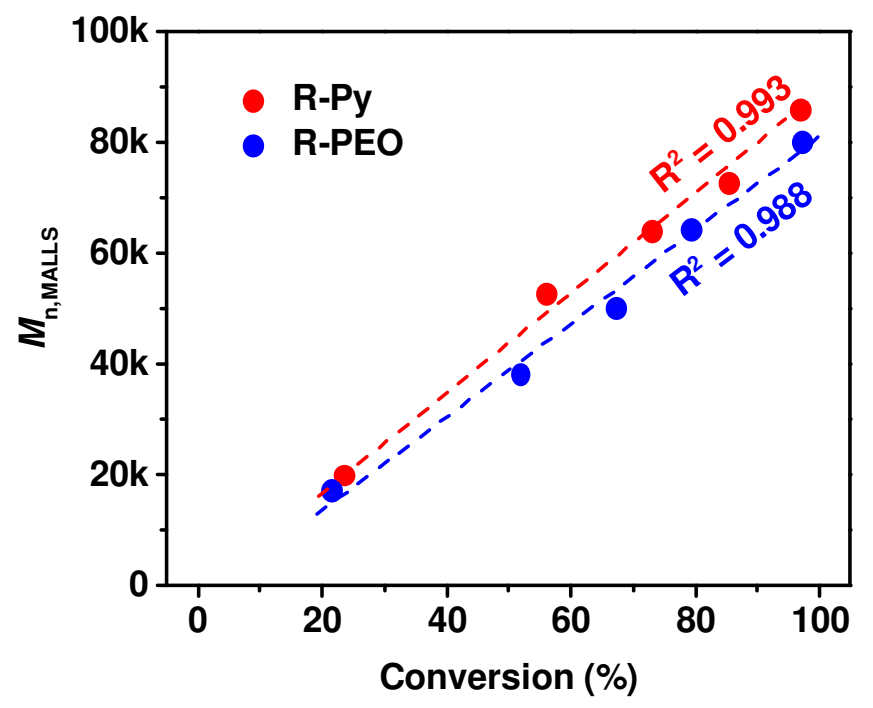

Figure S15. Evolution of number-average molecular weights $\left(M_{\mathrm{n}, \mathrm{MALLS}}\right)$ from the one-pot polymerizations of monomers R-Py and R-PEO, determined by SEC with a MALLS detector in THF.

A


B

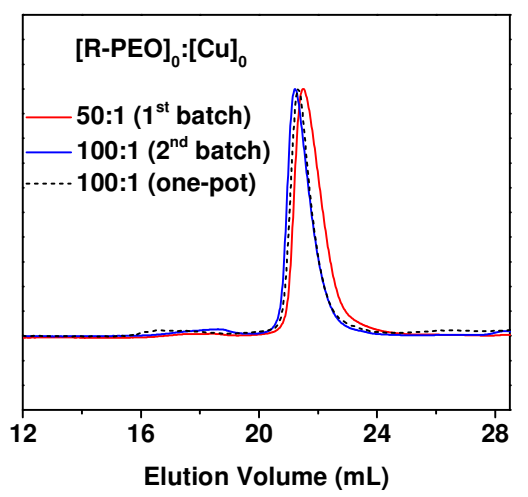

Figure S16. SEC traces (solid line, RI signal in THF) of HBPs produced by 
batchwise polymerization of (A) R-Py and (B) R-PEO, the final product of one-pot polymerization is shown as comparison (dashed line). (C) The $M_{\mathrm{n}, \mathrm{RI}}$ and $M_{\mathrm{w}} / M_{\mathrm{n}}$ as a function of $[\mathrm{R}]_{\text {total }}:[\mathrm{Cu}]_{0}$.

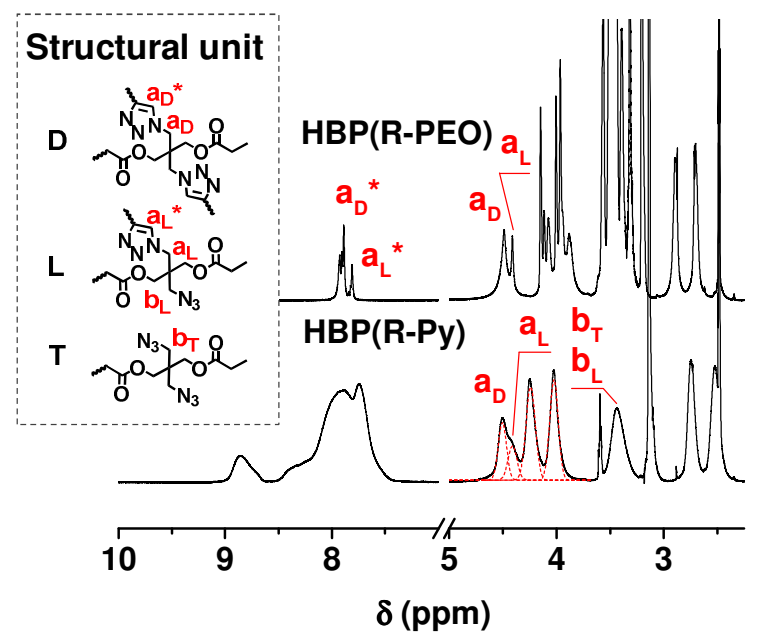

Figure S17. ${ }^{1} \mathrm{H}$ NMR spectra of $\mathrm{HBP}(\mathrm{R}-\mathrm{Py})$ and $\mathrm{HBP}(\mathrm{R}-\mathrm{PEO})$ in DMSO- $d_{6}$. Note: the triazole protons in $\mathrm{HBP}(\mathrm{R}-\mathrm{Py})$ were covered by the broad pyrene signals and couldn't be integrated. Instead, the partially overlapped methylene groups $a_{D}$ and $a_{L}$ at $\delta=4.51,4.41 \mathrm{ppm}$ were used to calculate the fractions of $\mathrm{D}$ and $\mathrm{L}$ units after peak fitting. 
A


B

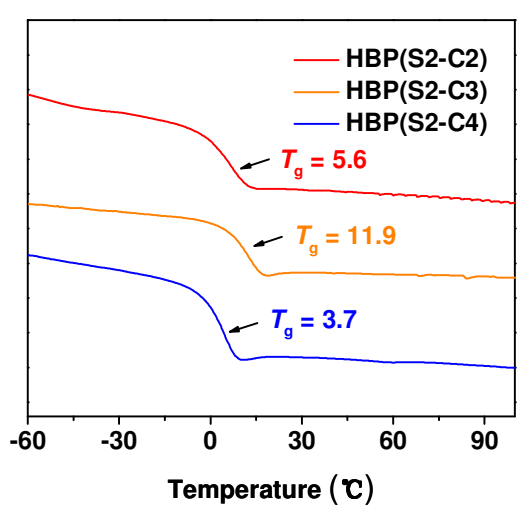

Figure S18. DSC curves of the hyperbranched polymers by using one-pot CuAAC method.

\section{References}

1. Gao, H.; Tsarevsky, N. V.; Matyjaszewski, K., Synthesis of degradable miktoarm star copolymers via atom transfer radical polymerization. Macromolecules $\mathbf{2 0 0 5}, 38$, 5995-6004.

2. Díaz, D. D.; Punna, S.; Holzer, P.; McPherson, A. K.; Sharpless, K. B.; Fokin, V. V.; Finn, M., Click chemistry in materials synthesis. 1. Adhesive polymers from copper-catalyzed azide-alkyne cycloaddition. J. Polym. Sci. Part A: Polym. Chem. 2004, 42, 4392-4403. 
3. Zhang, X.; Zhong, Z.; Zhuo, R., Preparation of azido polycarbonates and their functionalization via click chemistry. Macromolecules 2011, 44, 1755-1759.

4. Biannic, B.; Bozell, J. J.; Elder, T., Steric effects in the design of Co-Schiff base complexes for the catalytic oxidation of lignin models to para-benzoquinones. Green Chem. 2014, 16, 3635-3642.

5. Wu, X.-P.; Su, Y.; Gu, P., Catalytic enantioselective desymmetrization of 1, 3-diazido-2-propanol via intramolecular interception of alkyl azides with diazo (aryl) acetates. Org. Lett. 2014, 16, 5339-5341.

6. Tirino, P.; Conte, C.; Ordegno, M.; Palumbo, R.; Ungaro, F.; Quaglia, F.; Maglio, G., Y- and H- Shaped amphiphilic PEG-PCL block copolymers synthesized combining ring-opening polymerization and click chemistry: characterization and self-assembly behavior. Macromol. Chem. Phys. 2014, 215, 1218-1229.

7. Chimonides, G. F.; Sohdi, A. A.; Khaleghi, M. R.; Hurley, C. R.; Adams, D. J.; Topham, P. D., Facile synthesis of polymer-peptide conjugates via direct amino acid coupling chemistry. J. Polym. Sci. Part A: Polym. Chem. 2013, 51, 4853-4859.

8. Hong, S. Y.; Kwak, J.; Chang, S., Rhodium-catalyzed selective C-H functionalization of NNN tridentate chelating compounds via a rollover pathway. Chem. Commun. 2016, 52, 3159-3162.

9. Chan, T. R.; Hilgraf, R.; Sharpless, K. B.; Fokin, V. V., Polytriazoles as copper (I)-stabilizing ligands in catalysis. Org. Lett. 2004, 6 (17), 2853-2855.

10. www.ehs.ucsb.edu/files/docs/ls/factsheets/Azides_FS26.pdf 
11. Shi, Y.; Graff, R. W.; Cao, X.; Wang, X.; Gao, H., Chain-growth click polymerization of $\mathrm{AB}_{2}$ monomers for the formation of hyperbranched polymers with low polydispersities in a one-pot process. Angew. Chem. Int. Ed. 2015, 54, $7631-7635$.

12. Rodionov, V. O.; Presolski, S. I.; Díaz Díaz, D.; Fokin, V. V.; Finn, M., Ligand-accelerated $\mathrm{Cu}$-catalyzed azide-alkyne cycloaddition: a mechanistic report. $J$. Am. Chem. Soc. 2007, 129, 12705-12712.

13. Chouhan, G.; James, K., CuAAC macrocyclization: high intramolecular selectivity through the use of copper-tris (triazole) ligand complexes. Org. Lett. 2011, $13,2754-2757$. 